\title{
Erratum to: Bat attack! : an unusual cause of keratouveitis
}

Damrong Wiwatwongwana • Somsanguan Ausayakun •

Winai Chaidaroon • Atchareeya Wiwatwongwana

Published online: 29 July 2011

(C) Springer-Verlag 2011

Erratum to: Graefes Arch Clin Exp Ophthalmol

DOI 10.1007/s00417-011-1739-0

The correct figure for this paper is as below.

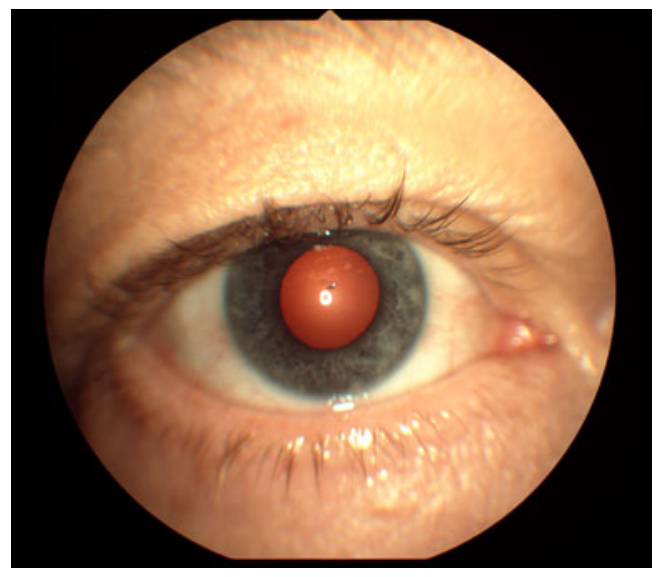

The online version of the original article can be found at http://dx.doi. org/10.1007/s00417-011-1739-0.

D. Wiwatwongwana $\cdot$ S. Ausayakun $\cdot$ W. Chaidaroon $\cdot$

A. Wiwatwongwana $(\triangle)$

Department of Ophthalmology, Chiang Mai University,

110 Inthawarorot Street, Amphur Muang,

Chiang Mai, Thailand 50200

e-mail: atchareeyaj@yahoo.com 